\title{
An optimization of effective energy management as a tool to facilitate managers
}

\author{
B. Geethanjali, L. M. Hansa \& M. Daniel \\ Department of Business administration, University of Madras, India \\ St. Mary's School of Management Studies, India
}

\begin{abstract}
Energy management in existing building services installations is an essential focus of contemporary facilities management. This paper discusses how the business is wasting the energy by emitting pollution. Energy management is not a one-off exercise; to be effective it needs to be an ongoing process. This research has addressed a quantitative approach for improving energy management through applying statistical techniques aimed at identifying and controlling factors linked to energy consumption rates at manufacturing plants. Wasting energy also reduces our profitability. For every $£ 1$ saved on energy costs, most UK businesses would have to make $£ 10$ worth of sales to make the same $£ 1$ of profit. The support programmers on energy efficiency can prove that most companies can reduce their energy costs by at least $10 \%$ through the implementation of simple housekeeping measures and by as much as $30 \%$ through the implementation of cost-effective measures.

Monitoring \& Targeting (M\&T) provides the means to identify where energy is used, where it is wasted and where to have the greatest effect in implementing energy savings measures. A good way of finding energy waste initially is to conduct an energy walk-round. The 5 steps to effective energy management are Commitment; Understand; Plan and Organise; Act; Control, Monitor and Review. It provides useful information when implementing these steps and their associated energy saving measures or the effect of other activities. These steps can show the deviation from expected patterns of energy use when controls are installed or re-set or production levels change. Finally, we identify the utilities invoices and ensure that we pay only for the fuel that is actually used, and compare to the current costs.
\end{abstract}

Keywords: energy management, green house gas (GHG), emission factor, carbon dioxide, fuel types. 


\section{Introduction}

The energy system consists of a chain of processes. It starts with the extraction or collection of primary energy sources, such as coal, crude oil, natural gas, biomass, uranium, and sunlight. Many industries are burning fossil fuels for their process heating. Major consumers of fossil fuels are the steel, cement, metal, petrochemical and ceramic industries. The emissions are carbon dioxide, nitrogen, oxygen, carbon monoxide, nitrogen oxides, sulphur dioxide, volatile organic compound, particulate and many other gases.

The energy content of the annual flow of these sources is often referred to as primary energy consumption. Primary energy is converted into energy carriers such as petrol and electricity, which are then converted into energy end-use provisions to provide the desired energy services. The annual flow of these energy carriers is called final energy consumption. Due to conversion losses, final consumption is less than primary consumption. Green house gas emissions in the region are largely carbon dioxide emissions from fossil fuel consumption in the end-use sectors or from energy conversion. In addition, carbon dioxide and methane emissions during extractions and transport play a role. The later products of combustion, which are considered pollutants are known to cause harmful effects on human beings and the environment.

\section{The 5 steps to effective energy management}

Energy management is not a one-off exercise; to be effective it needs to be an on-going process. Tracking the fuel consumption has never been easier, this short guide provides a structured approach that businesses can adopt to manage their energy use effectively. Opportunities to reduce environmental impacts can be found in all parts of the system. Carbon dioxide emissions can be lowered in the first part of the system by switching to energy sources with lower carbon content or with zero net carbon content for example switching to Hydropower, nuclear power, biomass or solar-based electricity.

In the second part of the system, lower conversion losses result in lower carbon emissions. One important option here is the combined generation of heat and power, which can raise the overall efficiency of converting fuels into electricity. Last but not least, demand for final energy can be reduced. Energy demand is determined by a complex of factors, including production and consumption patterns, income and available technology. Energy conservation measures result in the use of less energy services. Studies have indicated a large potential for energy conservation; this is seen, for instance in more efficient production methods in industry or the use of energy-efficient lighting in households.

\subsection{Commitment}

Make the company's policy to use energy efficiently and to keep carbon dioxide emissions to a minimum wherever possible. The key factors for success in 
energy management, as in any other management discipline, are Pressure for change, Clear shared vision (we must take staff along with us), Capacity for change (provide the resources: time $\&$ finance), Action (monitor performance $\&$ keep the communication channels open).

\subsection{Understand (establish the facts)}

The maxim "We can't manage what we don't measure" is especially true for energy management. The relatively high cost of transport fuel means that if we have a transport fleet, a high proportion of our overall energy costs will be diesel or petrol. This should record date, milometer reading, fuel purchased, cost of driver and service details. This data can be used to analyse vehicle performance and overall costs.

\subsection{Plan and organise}

The energy policy statement can be used to raise staff awareness and demonstrate the commitment of senior management. In a small business this may be the proprietor. A simple policy statement should set out the main objectives, together with the performance targets that need to be met to fulfill the objectives. Once objectives and targets have been agreed, action plans can be drawn up to drive the management plan forward and set down what needs to be done and when. All staff should be encouraged to participate. Incentive schemes can help ensure that actions are taken and that all staff contributes to energy efficiency measures.

\subsection{Act}

A good way of finding energy waste initially is to conduct an energy walkround. Ask key members of staff to accompany us - both to identify problems and opportunities, and to ensure they feel part of the assessment process. Where energy is being wasted because of lack of awareness, or procedures are being ignored, repair or maintenance work is needed to reduce energy costs, or there is a need for capital investment.

\subsection{Control, monitor and review}

Energy management should be a process of continuous control and improvement, not a one-off effort. We must therefore set up recording and monitoring systems to both check that targets are being met and to identify further cost reduction opportunities offering attractive returns on investment. The process of continuous recording and monitoring of energy use against consumption targets is known as Monitoring and Targeting (M\&T) and has been shown to be an effective management tool in numerous companies and organisations but it should be kept up. 


\section{Strategies for sustainable development}

This process couples energy awareness, energy conservation, and energy efficiency with the use of primary renewable energy resources.

\subsection{Energy awareness}

Energy production and efficient use are visible and interpreted components of the total sustainable development experience. The comprehensive advantages of sustainable alternatives over conventional approaches can be communicated through comparison of the source and amount of energy required for a particular service, and the associated environmental and economic cost implications.

\subsection{Energy conservation}

At the beginning of the planning process, a determination must be made to avoid energy-intensive or unnecessary operations. Facility design can contribute to energy conservation in several ways. Through recycling existing facilities, building only the minimum to satisfy the functional requirements, and having facilities serve multiple functions. Any food service associated with the development could also contribute to energy conservation.

\subsection{Energy efficiency}

Efficient methods, devices, and appliances should be employed at the sustainable development to conserve energy. Almost all facts of the development and visitor services and amenities can profit from recent innovations in energy efficiency.

\section{Combustion of fuels}

To calculate GHG emissions from the combustion of fuels, these guidelines make use of an activity statistic (e.g. annual fuel consumption in tonnes) and an emission factor (tonnes of $\mathrm{CO}_{2}$ per tonne of fuel combusted). For the purposes of these guidelines, emission factors give values in tonnes of $\mathrm{CO}_{2}$, rather than in kilograms.

\subsection{Coal-derived emissions}

Emissions from coal vary according to the net calorific value (NCV) of the fuel. This varies from one type of coal to another and therefore varies from country to country or region to region. The emission factors for as many countries as possible. If a relevant value is found for a particular country, it should be used. If not, the default value for coal is considered.

\subsection{Combustion of all fuels}

Carbon dioxide emissions from the most frequently used fuels, including coal, are shown below the emission factors are given for different units, to aid 
interpretation. Users should be able to find appropriate fuel consumption data in one of the units below. Once this is done, fuel consumption is multiplied by the appropriate factor.

\subsection{Simple rule of combustion}

Fuels need oxygen for burning or combustion. In most cases, air is used to supply the oxygen needed. Ideally, combustion needs the right amount of oxygen to get optimum efficiency. Too much air will result in heat loss through the chimney, too little air wastes fuel and the unburned fuel causes pollution

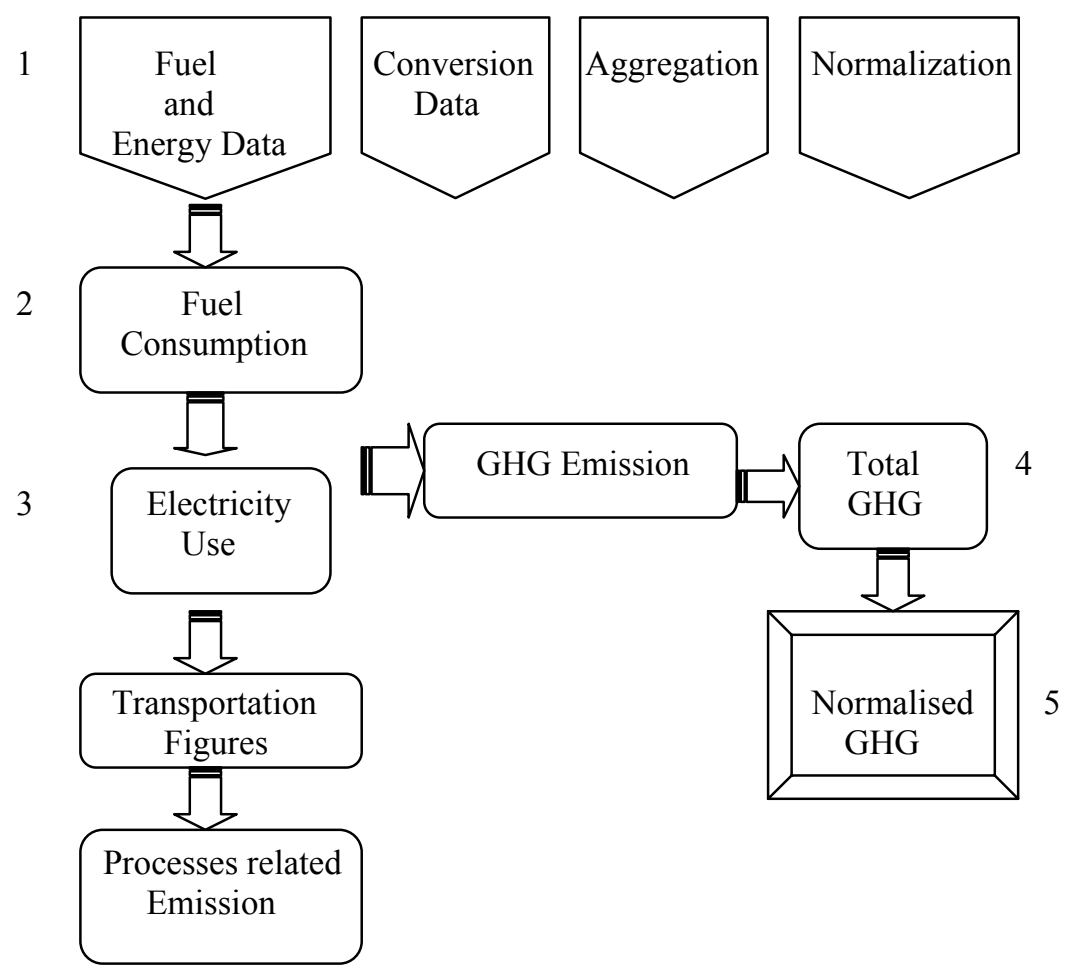

1 The process of deriving GHG emission through fuel and energy.

2 Air pollution is caused through fuel consumption, electricity use, transportation and process related emissions.

3 Fuel consumption, electricity use, transportation and process related emission gives out the green house gas.

4 The total GHG is calculated from the GHG emissions.

5 The total GHG leads to Normalized GHG, which is flexible and widely applicable.

Figure 1: Process of Deriving GHG. 
Table 1: $\quad$ Default carbon dioxide emissions from fuels.

\begin{tabular}{|c|c|c|c|c|}
\hline $\begin{array}{c}\text { Refined Petroleum } \\
\text { Products }\end{array}$ & $\begin{array}{c}\mathrm{tCO}_{2} \\
/ \text { therm }\end{array}$ & $\begin{array}{c}\mathrm{tCO}_{2} \\
/ \text { litre }\end{array}$ & $\begin{array}{c}\mathrm{tCO}_{2} \\
/ \mathrm{KWh}\end{array}$ & $\begin{array}{c}\mathbf{t C O}_{2} \\
/ \text { tonne }\end{array}$ \\
\hline Natural Gas & 0.005919 & & 0.0002020 & 2.93 \\
\hline Gas/ Diesel Oil & & 0.00268 & 0.0002667 & 3.19 \\
\hline $\begin{array}{c}\text { Liquid } \\
\text { Petroleum Gas }\end{array}$ & 0.006654 & 0.00165 & 0.0002271 & 2.95 \\
\hline
\end{tabular}

Non-carbon dioxide greenhouse gases generated by fuel combustion are mainly methane $\left(\mathrm{CH}_{4}\right)$ and nitrous oxide $\left(\mathrm{N}_{2} \mathrm{O}\right)$. Emissions of these gases are difficult to quantify but, according to Intergovernmental Panel on Climate Change, their warming contribution is probably minor compared to that of carbon dioxide. Rough estimates of $\mathrm{CH}_{4}$ and $\mathrm{N}_{2} \mathrm{O}$ contributions from the combustion of coal, natural gas and oil were calculated to be in the region of 1 per cent.

\section{Worksheet for the calculations of a company's GHG impact}

Select the type of fuel that is used in the industry. There may be different types of fuel. Some of the fuel types are coal, petrol, natural gas, gas/diesel oil, LPG, ethane, petroleum coke, refinery gas, jet kerosene etc. Basic units can be calculated in therms, litre, $\mathrm{kWh}$, tonne are shown in the table 1. The appropriate emission factors are entered in column 2 of the table. The emission factor can be either calculated based on the basic units or default value of the emission can be used. Enter the total in the final column. The total carbon value is shown in the bottom of the column represented as $(t)$.

\subsection{Steps to calculate emission from fuel use}

Step 1: First we have to see if there is likely to have process-related emissions, although the emission data should be known through the company's evaluation report.

Step 2: Enter emissions in appropriate basic unit column of the following table show. (Do not include the $\mathrm{CO}_{2}$ that you have been calculating for the Indicator.)

Step 3: Multiply basic unit with emission factors.

Step 4: Enter the results in ( $\mathrm{t})$. Add up the total $(\mathrm{t})$ and enter the total at the bottom of the column. 
Table 2: $\quad$ Emissions from fuel use.

\begin{tabular}{|c|c|c|c|c|c|}
\hline \multirow[t]{2}{*}{ Fuel types } & \multicolumn{2}{|c|}{ Basic unit } & \multicolumn{2}{|c|}{ Emission factors } & \multirow{2}{*}{$\begin{array}{l}\text { Amount } \\
\text { of } \\
\text { carbon } \\
\text { dioxide } \\
\text { released } \\
\text { (t) }\end{array}$} \\
\hline & Litres & Tonnes & $\mathrm{tCO}_{2} /$ litre & $\mathrm{tCO}_{2} /$ tonne & \\
\hline Petrol & 250 & & 0.00222 & 3.07 & 0.555 \\
\hline Natural Gas & & & & 2.93 & \\
\hline $\begin{array}{l}\text { Gas / Diesel } \\
\text { Oil }\end{array}$ & 100 & & 0.00268 & 3.19 & 0.268 \\
\hline Total & 350 & & & & 0.823 \\
\hline
\end{tabular}

\subsection{Calculation workings}

[1] In the above table consider fuel types of petrol and Gas/Diesel oil for calculation.

[2] The petrol and gas/diesel has an appropriate emission factors as $\mathrm{tCO}_{2}$ /litre respectively.

[3] Now multiply the basic unit of petrol (250 litres) with 0.00222 in emission factor.

[4] Calculate the Amount of carbon dioxide released ( $t$ ) for gas/diesel by multiplying 100 Litres with emission factor 0.00268 .

[5] Arrive at the total amount of carbon dioxide released with the respective rows.

[6] The total carbon dioxide released from petrol and gas/diesel.

[7] This total denotes the amount of $\mathrm{CO}_{2}$ released in the process of production.

\subsection{Calculation programme}

Calculation programme often provide a more accurate estimate than emission factors, although they may require considerably more effort in some cases. Because the programme inputs require process specific information, the results are process specific estimates. $\left(\mathrm{tCO}_{2}=\right.$ Total carbon dioxide)

\section{Exporting electricity or heat from CHP}

If there is an export of some of the electricity or heat from CHP then we need to work out the amount those exports in terms of its $\mathrm{CO}_{2}$ equivalent. Then subtract 
from the total $\mathrm{CO}_{2}$. The reason is, the $\mathrm{CO}_{2}$ from electricity is attributed to the end user, not the generator. For this type of indicator enter the data respectively as follows.

\section{Step 1}

Calculate the Total $\mathrm{CO}_{2}$ from fuel use of the CHP,

Enter the total $=$ TOTAL $\mathrm{CO}_{2}$

$\mathrm{CO}_{2}=$ Carbon dioxide; $\mathrm{CHP}=$ Combined Heat $\&$ power; $\mathrm{kWh}=$ kilowatts

\section{Step 2}

Require to work out the $\mathrm{CO}_{2}$ emission factor for the electricity that is produced. The procedure can be done by dividing the amount of $\mathrm{CO}_{2}$ of the $\mathrm{CHP}$ by the amount of electricity and heat that is produced. The following formulas helps in calculation of total carbon dioxide $\left(\mathrm{tCO}_{2}\right)$ per kilowatts of electricity produced.

$\mathrm{tCO}_{2}$ per $\mathrm{kWh}$ of Electricity produced $=$

\section{$2 \mathrm{X}$ Amount of Fuel used in $\mathrm{kWh} \mathrm{X} \mathrm{t} \mathrm{CO} / \mathrm{kWh}$ Emission Factor}

$2 \mathrm{X}$ Electricity produced in $\mathrm{KWh}+$ Heat Produced in $\mathrm{kW}$

\section{Step 3}

Step 3 is very similar to Step 2 but calculates the $\mathrm{CO}_{2}$ emission factor for the heat that produced by the following formula.

$\mathrm{tCO}_{2}$ per $\mathrm{kWh}$ of Heat Produced $=$

\section{Amount of Fuel used in $\mathrm{kWh} \mathrm{X} \mathrm{t} \mathrm{CO}_{2} / \mathrm{kWh}$ Emission Factor}

$2 \mathrm{X}$ Electricity Produced in $\mathrm{kWh}+$ Heat Produced in $\mathrm{kWh}$

\section{Step 4}

Enter the amounts of electricity and heat that is exported, in $\mathrm{kWh}$. The value is then multiplied by the new emission factors that are calculated in steps 2 and 3 . The value thus obtained gives the total for the $\mathrm{CO}_{2}$ emissions exported.

$\mathrm{CO}_{2}$ from Electricity Export $=\mathrm{KWh}$ of Electricity exported $\mathrm{X} \quad \mathrm{tCO}_{2}$ per $\mathrm{kWh}$ of electricity produced

$\mathrm{CO}_{2}$ from Heat Export $\quad=\mathrm{KWh}$ of Heat exported $\mathrm{X} \mathrm{tCO}_{2}$ per $\mathrm{kWh}$ of Heat produced

Total $\mathrm{CO}_{2}$

$=$ Add the two figures together to give your total export of $\mathrm{CO}_{2}$

\section{Step 5}

The final step is to subtract the $\mathrm{CO}_{2}$ that have exported from the total $\mathrm{CO}_{2}$ produced, given in the Step 1. This procedure gives the total $\mathrm{CO}_{2}$ from $\mathrm{CHP}$, 
taking into account the $\mathrm{CO}_{2}$ exported. The final figure should be entered in Column 2 in Worksheet There are two options to consider if we use a mix of fuels for our CHP and we also export some of the electricity or heat.

Calculate the total fuel input from all the fuels we have used in our CHP and then the total $\mathrm{CO}_{2}$ Now divide the total $\mathrm{CO}_{2}$ by total fuel input to get the average $\mathrm{CO}_{2}$ emission factor per tonne of fuel, which can be used in table 2. For example:

Table 3: $\quad$ Calculation of Total $\mathrm{CO}_{2}$.

\begin{tabular}{|l|c|l|c|l|c|}
\hline Fuel Types & Amount & & Emission factor & & $\mathrm{CO}_{2}$ \\
\hline Coal & 500 & $\mathrm{X}$ & 1.85 & $=$ & 925 \\
\hline Refinery Feedstock & 3502 & $\mathrm{X}$ & 3.25 & $=$ & 11382 \\
\hline Petroleum Coke & 45 & $\mathrm{X}$ & 3.09 & $=$ & 139 \\
\hline Total Fuel Input & 4047 & & Total $\mathrm{CO}_{2}$ & & 12446 \\
\hline
\end{tabular}

Total $\mathrm{CO}_{2} /$ Total Fuel Input $=\mathrm{CO}_{2}$ Emission factor

$12446 / 4047=3.075 \mathrm{tCO}_{2}$ per tonne of fuel

b) Alternatively, if we want to be more accurate, we can go through the calculation process for each individual fuel. Although more time-consuming, this would be more accurate than using one average emission factor for all the fuels that is in use.

\section{Suggestions}

The generation of waste by companies can lead to the production of highly potent greenhouse gases $\mathrm{CO}_{2}$ and methane $\mathrm{CH}_{4}$. Minimization of the waste emission to certain level can be done by the following methods.

- The five steps to effective energy management: The commitment, understand, plan and organise, act, control, monitor and review this short guide provides a structured approach which will help to reduce environmental impacts of carbon dioxide emission.

- Heating value: One has to be careful in purchasing fuel for their combustion system. The cost is one of the deciding factors. Other factors shall include the specification of fuels. Heating value is important, and so is the composition of fuel.

- Hydro electric power: Government and industries should try implementing, using hydro electric power instead of fuel, which causes pollution. Usage of hydroelectric power will reduce emitting pollution.

- Land filling or solid waste disposal: Waste disposal practices vary substantially between countries, even down to specific site operators. The composition of industrial wastes varies considerably industry by industry, and company by company. 
- Waste water handling: The organic content of wastewater may vary considerably. Wastewater treatment systems determine the level of aerobic conditions. Temperature and other factors influence methane production.

\section{Conclusion}

The effect of greenhouse gases on global warming is the most important environmental issue facing the world today. Our knowledge of the underlying causes of climate change is growing, but the problem brims with uncertainties, raising serious scientific and ethical questions. The fact that added $\mathrm{CO}_{2}$ can lead to a large global warming. The total carbon dioxide emitted in the atmosphere is calculated for analysing the wastage of energy during the production process and amount of loss incurred. The calculation thus shows the amount of carbon dioxide emitted and the areas where preventive steps should to taken to reduce the wastage of cost and time. The loss can be controlled effectively by analysing the areas of wastage emissions while during process of manufacturing. Companies with little or no experience can follow the five steps effectively. It can control energy management, but it takes time to go through the process systematically. When they adopt this process, wastage is reduced which will create profitability to the concerns. If the company does not use combined power, heat systems and electricity produced by CHP all we have to do is to replace the generic international emission factors and conversion factors with appropriate national data.

\section{References}

[1] BP Amoco, (1997) Protocol for the Calculation of Carbon Dioxide Emissions

[2] IPCC (1996a) Greenhouse Gas Inventory Reference Manual, Revised 1996 IPCC Guidelines for National Greenhouse Gas Inventories

[3] US department of energy - energy efficiency and renewable energy - June 2006

[4] Industrial Energy Management: Principles and Applications -by Giovanni. Petrecca

[5] Guide to energy management by B.L. Capehart, W.C. Turner, W.J. Kennedy

[6] Energy management handbook: By Wayne C.

[7] Marland \& Pippen (1990) United States Emission of $\mathrm{CO}_{2}$ to Earth's Atmosphere by Economic Activity Energy system \& Policy, Vol. 14 pp 319336.

[8] Hart S. and Ahuja, G(1996) Does it pay to be green? An Empirical examination between Emission reduction and firm performance, Business strategy and the Environment. Vol 5 pp 30-57. 